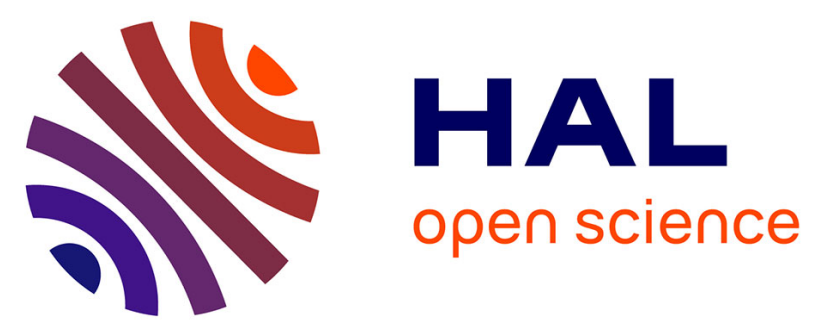

\title{
Diagnosis of Alzheimer's disease patients with rapid cognitive decline in clinical practice: interest of the deco questionnaire.
}

Laure Carcaillon, Gilles Berrut, François Sellal, Jean-François Dartigues, Sophie Gillette, Jean-Jacques Péré, Isabelle Bourdeix

\section{To cite this version:}

Laure Carcaillon, Gilles Berrut, François Sellal, Jean-François Dartigues, Sophie Gillette, et al.. Diagnosis of Alzheimer's disease patients with rapid cognitive decline in clinical practice: interest of the deco questionnaire.. Journal of Nutrition, Health \& Aging, 2011, 15 (5), pp.361-6. inserm-00590465

\section{HAL Id: inserm-00590465 https://www.hal.inserm.fr/inserm-00590465}

Submitted on 3 May 2011

HAL is a multi-disciplinary open access archive for the deposit and dissemination of scientific research documents, whether they are published or not. The documents may come from teaching and research institutions in France or abroad, or from public or private research centers.
L'archive ouverte pluridisciplinaire HAL, est destinée au dépôt et à la diffusion de documents scientifiques de niveau recherche, publiés ou non, émanant des établissements d'enseignement et de recherche français ou étrangers, des laboratoires publics ou privés. 
1 Diagnosis of Alzheimer's disease patients with Rapid Cognitive

2 Decline in clinical practice: interest of the Deco questionnaire.

3 L. Carcaillon, $\mathrm{MSc}^{1}$, G. Berrut, $\mathrm{MD}, \mathrm{PhD}^{2}$, F. Sellal, $\mathrm{MD}^{3-4}$, J.F. Dartigues, MD, $\mathrm{PhD}^{1 ; 5}$, S.

4 Gillette, $\mathrm{PhD}^{6-7}$, J.J. Péré ${ }^{8}$, I. Bourdeix ${ }^{9}$

1. Inserm, CR897, Université Victor Segalen Bordeaux2, Bordeaux, France

2. University Hospital Center, Department of gerontology, Université de Nantes, France

3.Inserm, U692, University of Strasbourg, France

4. CMRR, Neurology Department, Hôpitaux Civils de Colmar, France

5. University Hospital Center, Université Victor Segalen Bordeaux2, Bordeaux, France

6. Gerontopole, Toulouse University Hospital, Department of Internal Medicine and Geriatrics, Purpan

University Hospital, Toulouse, France

7. Inserm, U558, University of Toulouse III, Toulouse, France

8. Novartis Pharma S.A.S., clinical research, Rueil-Malmaison, France

9. Novartis Pharma S.A.S., biometry, Rueil-Malmaison, France

Corresponding author:

\section{Laure CARCAILLON}

Inserm-Cesp UMR-S 1018 - Hormones and Cardiovascular Disease

Hopital Paul Brousse, Inserm bat.15/16

16, avenue Paul Vaillant-Couturier

94807 Villejuif Cedex

Email: laure.carcaillon@inserm.fr

Tel.: + 33145595145

Fax: + 33145595170

\section{Tables 6}

31 Figures 2

Word count: 


\section{Abstract}

2

3 Background: Patients with Alzheimer's disease (AD) who deteriorate rapidly are likely to

4 have a poorer prognosis. There is a clear need for a clinical assessment tool to detect such a

5 decline in newly diagnosed patients.

6 Objective: To identify the predictive factors of rapid cognitive decline (RCD) in a cohort of

7 patients with mild to moderate $\mathrm{AD}$; and to validate a self-questionnaire for caregivers as a

8 diagnostic tool for rapid decline.

9 Design and analysis: an open-label, observational, 12-month, multicenter, French study. Physicians were asked to record data of three eligible rivastigmine naïve (or on rivastigmine for $<1$ year) AD patients. Risk factors of RCD and the detection power of the Déterioration Cognitive Observée scale (Deco), a 19 item self-questionnaire for caregivers, were assessed at

13 endpoint using regression analyses.

14 Results: Out of the 361 patients enrolled in the study, 91 (25.2\%) were excluded due to loss of 15 follow-up. Among subjects using cholinesterase inhibitors or memantine, 161 (59.6\%) 16 experienced a stabilization $(29.2 \%)$ or an improvement $(30.4 \%)$ in global functioning as measured by the CGI-C. Sixty of the remaining 204 patients retained for analysis $(29.6 \%, \mathrm{CI}$ 95\% [23.4; 35.8]) lost three or more points on the MMSE score between the inclusion and one of the follow-up visit. In the multivariate logistic regression analysis, institutionalization, higher level of education and the loss of 3 points or more on the MMSE were found to be significant predictors of a rapid cognitive loss in this population. The threshold which maximizes the predictive values of the Deco score as a diagnostic tool of rapid cognitive decline was significantly different according to the age of the patient (below or over 75 years old). A score below 16 for patients $<75$ years old and below 14 for patients $\geq 75$ years old consistently predicted a RCD within the next year.

26 Conclusion: The Deco test appears to be a simple tool to alert the physician to the possibility of an aggressive course of the disease which warrants particular management.

Key words: Alzheimer's disease, rapid cognitive decline, diagnostic tool 
INTRODUCTION

Neurodegenerative dementias such as Alzheimer Disease (AD) are characterized by a progressive cognitive decline. However, the rate of progression can be highly variable from one patient to another [1] and some patients could have a more rapid cognitive decline (RCD). These patients are likely to have a poorer prognosis, with a higher mortality rate or a lower survival rate without severe dementia, than those with slower progression rates [1-3].

A prospective observational study performed in a population of $455 \mathrm{AD}$ patients followed for at least one year, demonstrated that the risk of deterioration was significantly decreased in patients taking cholinesterase inhibitors (ChEIs) for at least one year compared to untreated patients [4]. To date, rivastigmine is the only drug which has been specifically studied in patients with RCD. A meta-analysis of four 6-month, double-blind, placebocontrolled phase studies [5] showed that patients who experienced rapid decline, i.e. a decline of at least 4 points of the ADAS-cog score, during 26 weeks of placebo treatment, improved significantly more after 12 weeks of rivastigmine therapy than those who had declined by less than 4 points in the first 26 weeks. Thus, identifying AD patients at risk of RCD is important as these patients might benefit from specific primary or secondary care including more frequent clinical and neuropsychological evaluations, more frequent adaptation of drug treatment and more effective support for the caregiver.

Several factors may predict RCD in AD patients: cognitive status, presence of ExtraPyramidal Signs, psychotic symptoms and hallucinations, prominent sub-cortical pathology with attention and executive deficits and poor nutrition [6; 7]. However many of these factors are of limited interest in a clinical setting for individual patients as it is difficult to obtain valid information about most of them during the time of a consultation. There is thus a clear need for a simple clinical assessment tool, drawing on caregiver input, to detect RCD in recently diagnosed patients. The "Détérioration Cognitive Observée" (Deco) scale is a 19-item questionnaire administered to a person with at least a monthly contact with the patient. Its aim is to evaluate the change in cognitive functioning of the patient over the previous year. This instrument has been shown to be highly sensitive to early changes in cognitive functioning in previous studies [8].

The objectives of the prospective study we report here were to identify the predictive factors of RCD in a cohort of patients with mild to moderate AD ; and to analyze the predictive value of a self-questionnaire for caregivers (the Deco score) as a simple diagnostic tool for RCD. 
1 PATIENTS AND METHODS

2 Study Design

EXPLORE was an open label, observational cohort study, 12-month, multicenter,

4 French study for which 350 neurologists, geriatricians and psychiatrists were contacted in

5 order to finally include 250 of them. Each was asked to record data of three eligible patients.

6 Eligibility criteria included: outpatients with AD over fifty years old, satisfying the criteria of the fourth edition of the Diagnostic and Statistical Manual of Mental Disorders (DSM-IV) for dementia and those of NINCDS-ADRDA Work Group; with Mini-Mental State Examination (MMSE) [9] scores between 10 and 26; initiating therapy for the first time with rivastigmine or having already received rivastigmine for less than one year; with a planned follow-up visit within 12 months of enrolment and a caregiver's burden assessment; with an available informant. Patients not treated according to the product labeling, patients involved in a clinical trial or patients treated by an experimental drug within the previous 4 weeks were excluded. Investigators were advised to follow product labeling.

The Steering Committee, the French National Council of Medical Practitioners Order (CNO) and the National Council of Informatics and Freedom (CNIL) approved the study. All the patients were given a study information sheet.

For the present analysis, only subjects followed during twelve months were considered $(\mathrm{n}=204)$. Figure 1 is a detailed flow chart of patients 'selection and exclusion.

\section{Study assessments}

At study entry, a detailed medical history of each patient was taken and baseline and follow-up assessments of cognitive performances was performed.

Rapid cognitive decline was defined as a decline of at least three points of MMSE during the one year of follow-up. The following potential predictive factors of RCD were collected at baseline: MMSE, presence of behavioral disorders reported by the patient or his family (delusions, hallucinations, agitation/aggression), presence of extrapyramidal signs, lack of autonomy for the key Instrumental Activities of Daily Living (IADL) items (budget, phone, drugs, transport) [10], lack of stabilization with previous IChE or memantine treatment, Body Mass Index (BMI) and level of education. The clock drawing test[11], the 5-word test[12] and a verbal fluency test were also taken into account.

The 19-item caregiver questionnaire, the Deco score was collected at the end of the 12month follow-up. 
Safety (vital signs, adverse events and a physical examination) regarding the use of

2 IChE was assessed throughout the study as needed.

3

4

\section{Data analysis}

Characteristics of the patients who were seen at the12-month visit were compared to those of all subjects enrolled in the study by appropriate univariate statistical tests.

Using simple and multiple logistic regressions, we studied the risk of RCD according to baseline characteristics of the patients. The multivariate analysis included all variables significantly associated with the risk in the univariate analysis at a p-value $<0.10$. Moreover, we compared mean values of the Deco score according to some baseline characteristics of the patients. We used student t-test for the comparison.

In addition, we ran a Receiver Operating Characteristic (ROC) analysis to detect the best threshold of diagnosis of RCD for the Deco score. Sensitivity, specificity, positive and negative predictive values were calculated for the best thresholds found from the observed ROC curve. We systematically sought for interactions between age and Deco score on the risk of RCD. Indeed, the risk of rapid decline is higher among younger subjects so we hypothesized that the predictive value of Deco might have a differential association with RCD according to age. SAS statistical software version 9.2 was used to perform analyses.

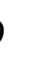

0

\section{RESULTS}

\section{Patients}

Three hundred and sixty one patients were enrolled in the study by 152 neurologists, geriatricians and psychiatrists. Among subjects using ChEI or memantine, 161 patients $(59.6 \%)$ experienced a stabilization $(29.2 \%)$ or an improvement $(30.4 \%)$ in global functioning, as measured by the CGI-C. One hundred and fifty seven patients (25.2\%) were excluded from analysis because of loss of follow-up between baseline and the 12-month follow-up ( $n=151$ ) or missing value on MMSE ( $n=6$ ) (figure 1). Baseline characteristics of the analyzed and enrolled populations were comparable (Table 1). In the analyzed population, 89 patients $(43.6 \%)$ had received prior ChEI treatment and $115(56.4 \%)$ were de novo patients. Of the 89 patients who had received prior ChEI treatment, 63 patients were already treated by rivastigmine and 26 discontinued from a previous treatment by another ChEI. 
1 There were more women than men (58.3\% versus $41.7 \%)$ and the mean age was

2 approximately 78 years (range 51-102 years). At baseline, patients included in this analysis

3 had a mean MMSE score of $19.7 \pm 4.4$.

4 For patients who had been previously treated by ChEIs, the mean duration of treatment before starting the study was $14.0 \pm 14.3$ months with a mean MMSE decrease of $2.1 \pm 3.0(-1.1 \pm$ 2.6 for rivastigmine; $-4.1 \pm 2.8$ for donepezil and $-3.6 \pm 3.0$ for galantamine).

For the analyzed population, the MMSE decrease within the previous year was only known for 101 patients (i.e., data missing for 103). The mean follow-up period was $377.6( \pm 61.2)$ days.

\section{Predictive factors of cognitive decline}

Sixty of the 204 patients retained for analysis $(29.4 \%$, 95\%CI [23.4; 35.8]) were qualified as rapid cognitive decliners as they lost three or more points on the MMSE score between the inclusion and the 12-month follow-up visit.

Table 2 shows that the demographic and neuropsychological characteristics significantly associated with RCD by univariate analysis are: living in an institution and a high level of education (p-value < 0.03). In addition, a weaker level of autonomy and the loss of 3 points or more on the MMSE during the year prior to inclusion tended to be associated with RCD (p-value < 0.07). As there was a high number of missing values for the variable "loss of 3 points or more on the MMSE during the year prior inclusion", two multivariate models were performed to analyze the risk of RCD (table 3). Model 1 included residential status, level of education and loss of autonomy. In this model, only the level of education remained significantly associated with $\mathrm{RCD}(\mathrm{OR}=2.21,95 \%$ I.C. $(1.12-4.37))$. The second model (model 2) was further adjusted for the loss of more than 3 points on MMSE prior inclusion. In this model, the level of education and the loss of more than 3 points on MMSE were significant predictors of rapid decline.

\section{The Deco questionnaire}

The mean Deco questionnaire score was $19.0 \pm 8.8$. It was significantly different between rapid decliners $(15.5[13.6 ; 17.5])$ and slow decliners $(20.3[18.8 ; 21.8])$ (p for difference $=0.001)($ table 4$)$.

Table 4 displays the mean of the Deco score according to baseline characteristics of the patients. No significant association was found for socio-demographic characteristics. 
1 Significant lower values of Deco scores were observed for subjects with low level of (p-value $2=0.07)$.

Figure 2 shows the ROC curve of the predictive value of RCD according to the Deco score. Visually, the threshold which maximizes the specificity and the sensitivity of the score seems to be between 16 and 18. Table 5 reports the risks of RCD as well as the results from a sensitivity/specificity analysis for three thresholds (a Deco score $<=16,<=17$ or $<=18$ ). The best model in terms of risk was observed for the threshold of 16 . The risk of RCD for a patient having a score $<=16$ for the Deco questionnaire was three times higher than for a patient scoring over $16(\mathrm{p}=0.002)$. However, we found an interaction between age and the threshold of 16 on the risk of RCD. For this threshold, the risk of RCD was significantly increased among younger subjects (age $<75$ ) but not among older ones (respectively OR = 6.7, 95\%C.I. (1.8-25.1) and $\mathrm{OR}=2.1$, 95\%C.I. (0.9-4.8)). As a consequence we ran new analyses to evaluate the best predictive thresholds of RCD according to age-group (below or over 75). Results are reported in table 6 . We found that a threshold of 16 among subjects aged below 75 years old and a threshold of 14 for subjects older than 75 years old maximized the predictive values of the Deco score. Sensitivity, specificity and predictive values were consistently better than in the analysis pooling the two age-groups.

\section{DISCUSSION}

In this one year observational study we found that $29.4 \%$ of patients with AD lost 3 points or more at the MMSE score and were thus classified as rapid decliners over the study period. Living in an institution, having a high educational level and being impaired for at least two activities in daily living were significantly associated with RCD. Finally, the Deco score was differently related to the occurrence of RCD according to the age of the patient. A threshold of 16 was found to be the best diagnostic tool for RCD among subjects aged $<75$ years old while a threshold of 14 was found for subjects aged $\geq 75$ years old.

In our study we found a relatively low proportion of rapid decliners compared with other studies. Although other definitions of cognitive decline have been proposed [3; 13], a decline of 3 points or more of the Mini-Mental State Examination (MMSE) over one year is a commonly used definition of RCD. Indeed, several clinical or population-based studies have shown that this threshold of decline was strongly linked to mortality or entry in an institution $[2 ; 14]$. Moreover, the use of MMSE compared to other neuropsychological tests is the only one to fit with clinical practice. In addition, all our patients were using ChEI so the low 
1 proportion of rapid decliners found is consistent with the fact that rivastigmine, which is the only therapy studied in this population, has been shown to reduce the risk of rapid cognitive decline in patients using ChEI $[4 ; 15]$.

As AD patients with RCD have a poorer prognosis, they warrant particular attention from the clinician. Previous efforts have been made to identify risk factors of rapid decline which could be targeted for timely introduction of preventive actions $[6 ; 7 ; 16 ; 17]$. In our study, demographic factors as living in institution and high level of education, and previous rapid decline appear as independent factors correlated with a rapid disease progression, while the usual clinical predictors as poor nutritional status, psychotic or extrapyramidal signs were not found to be correlated. While this lack of correlation could be attributed to the greater benefits of rivastigmine in this population [5; 7], the low proportion of patients in our study with such clinical symptoms at baseline should also be taken into account.

Even if certain factors may be good predictors of rapid decline, available data remain contradictory [18] and are not sufficient or relevant in routine practice for clinical-decision making, especially for newly diagnosed patients. In this respect, we aimed to assess the capacity of a new scale to evaluate the one-year change in cognitive functioning of patients according to their caregiver (or a person in contact with them). The Deco questionnaire used in this study appeared to be a valuable clinical tool for the detection of RCD. Indeed, when taking into account the age of the patients, thresholds of detection were strongly associated with RCD. A Deco score of less than 16 among patients under 75 years old, and of less than 14 among patients over 75 years old, was found to be strongly associated with RCD. The risk of being a rapid decliner was 3 to 6 times higher among patients whose caregiver scored less than the threshold found for the Deco score. Moreover, the positive predictive value was close to $50 \%$ in the younger age-group which is a relevant value for clinical decision making. Indeed, it indicates that if an informant reports a score lower than 16 for a patient, there is $50 \%$ chance that this subject has actually encountered a rapid decline within the previous year. Preventive care for these subjects appears necessary and will be useful for one patient out of 2. In addition, it is to be noted that the predictive values of the Deco score were better in the younger group of patients. This finding may be explained by the fact that older patients complain less than younger ones and they, as well as their caregivers, may attribute their changes in cognitive performances to age rather than to a pathological process. They may report less frequently little cognitive changes. Hence, the Deco questionnaire could represent a simple way of detecting patients with a high probability of rapidly progressing symptoms and thus to adapt disease management accordingly. 
While our results are promising, this study does have some limitations. It remains

2 merely a historical comparison and no definitive conclusion can be drawn. Moreover, only a

3 low number of neurologists finally recruited patients. Together with the fact that a quarter of

4 the patients were lost to follow-up, this could have introduced a bias. Our sample may not be

5 fully representative of the AD population and thus our results should be interpreted with

6 caution. Nonetheless, when enrolled patients' baseline characteristics were compared to those

7 of the finally analyzed population, no difference was found, especially in the items of level of

8 autonomy and cognitive impairment.

9 Overall this study suggests that AD patients at risk of RCD can be identified in the 10 setting of a regular consultation by means of the Deco questionnaire. Once alerted to the 11 possibility of an aggressive disease course, the physician could pay particular attention to 12 these patients and adapt disease management accordingly. 


\section{REFERENCES}

2 1. Doody R S, Massman P, \& Dunn J K. (2001). A method for estimating progression rates in Alzheimer disease. Arch Neurol, 58(3), 449-454.

2. Carcaillon L, Peres K, Pere J J, Helmer C, Orgogozo J M, \& Dartigues J F. (2007). Fast cognitive decline at the time of dementia diagnosis: a major prognostic factor for survival in the community. Dement Geriatr Cogn Disord, 23(6), 439-445.

3. Helmer C, Andrieu S, Peres K, Orgogozo J M, Vellas B, \& Dartigues J F. (2007). Predictive value of 6-month decline in ADAS-cog for survival without severe Alzheimer's disease. Dement Geriatr Cogn Disord, 23(3), 168-174.

4. Gillette-Guyonnet S, Andrieu S, Cortes F, Nourhashemi F, Cantet C, Ousset P J, et al. (2006). Outcome of Alzheimer's disease: potential impact of cholinesterase inhibitors. $J$ Gerontol A Biol Sci Med Sci, 61(5), 516-520.

5. Farlow M R, Small G W, Quarg P, \& Krause A. (2005). Efficacy of rivastigmine in Alzheimer's disease patients with rapid disease progression: results of a meta-analysis. Dement Geriatr Cogn Disord, 20(2-3), 192-197.

6. Dumont C, Voisin T, Nourhashemi F, Andrieu S, Koning M, \& Vellas B. (2005). Predictive factors for rapid loss on the mini-mental state examination in Alzheimer's disease. J Nutr Health Aging, 9(3), 163-167.

7. Gauthier S, Vellas B, Farlow M, \& Burn D. (2006). Aggressive course of disease in dementia. Alzheimers Dement, 2(3), 210-217.

8. Ritchie K, Artero S, \& Touchon J. (2001). Classification criteria for mild cognitive impairment: a population-based validation study. Neurology, 56(1), 37-42.

9. Folstein M F, Folstein S E, \& McHugh P R. (1975). "Mini-mental state". A practical method for grading the cognitive state of patients for the clinician. J Psychiatr Res, 12(3), 189-198.

10. Lawton M P, \& Brody E M. (1969). Assessment of older people: self-maintaining and instrumental activities of daily living. Gerontologist, 9(3), 179-186.

11. Galluzzi S, Cimaschi L, Ferrucci L, \& Frisoni G B. (2001). Mild cognitive impairment: clinical features and review of screening instruments. Aging (Milano), 13(3), 183-202.

12. Dubois B. (2001). L'épreuve des cinq mots. Neurol Psychiatrie Gériatr, 1, 40-42.

13. Soto M E, Andrieu S, Arbus C, Ceccaldi M, Couratier P, Dantoine T, et al. (2008). Rapid cognitive decline in Alzheimer's disease. Consensus paper. J Nutr Health Aging, 12(10), 703-713. 
14. O'Hara R, Thompson J M, Kraemer H C, Fenn C, Taylor J L, Ross L, et al. (2002). Neurol, 15(4), 233-238.

15. Lopez O L, Becker J T, Wisniewski S, Saxton J, Kaufer D I, \& DeKosky S T. (2002). Cholinesterase inhibitor treatment alters the natural history of Alzheimer's disease. $J$ Neurol Neurosurg Psychiatry, 72(3), 310-314.

16. Marquis S, Moore M M, Howieson D B, Sexton G, Payami H, Kaye J A, et al. (2002). Independent predictors of cognitive decline in healthy elderly persons. Arch Neurol, 59(4), 601-606.

17. Musicco M, Palmer K, Salamone G, Lupo F, Perri R, Mosti S, et al. (2009). Predictors of progression of cognitive decline in Alzheimer's disease: the role of vascular and sociodemographic factors. J Neurol, 256(8), 1288-1295.

18. Teri L, McCurry S M, Edland S D, Kukull W A, \& Larson E B. (1995). Cognitive decline in Alzheimer's disease: a longitudinal investigation of risk factors for accelerated decline. J Gerontol A Biol Sci Med Sci, 50A(1), M49-55. 
Table 1 - Comparison of baseline characteristics of enrolled and analyzed patients

\begin{tabular}{|c|c|c|}
\hline & $\begin{array}{r}\text { Enrolled Population } \\
N=361\end{array}$ & $\begin{array}{r}\text { Analyzed population } \\
N=204\end{array}$ \\
\hline Age (years), $\mathrm{m} \pm \mathrm{SD}$ & $77.9 \pm 7.55$ & $78.0 \pm 7.5$ \\
\hline Sex (female) & $215(59.6 \%)$ & $119(58.3 \%)$ \\
\hline \multicolumn{3}{|l|}{ Level of education } \\
\hline * long secondary school & $92(25.6 \%)$ & $53(26.0 \%)$ \\
\hline Residential status (out-patients) & $302(83.7 \%)$ & $169(82.8 \%)$ \\
\hline Duration of the disease (years), $\mathrm{m} \pm \mathrm{SD}$ & $1.8 \pm 1.5$ & $1.8 \pm 1.4$ \\
\hline Psychotropic drugs & $170(47.1 \%)$ & $106(52.0 \%)$ \\
\hline * neuroleptics & $31(8.6 \%)$ & $20(9.8 \%)$ \\
\hline * antidépressive drugs & $98(27.1 \%)$ & $60(29.4 \%)$ \\
\hline \multicolumn{3}{|l|}{ Previous treatment by ChEI } \\
\hline * none & $214(59.3 \%)$ & $115(56.4 \%)$ \\
\hline * rivastigmine & $97 \quad(26.9 \%)$ & $63(30.9 \%)$ \\
\hline * other ChEI & $50 \quad(13.8 \%)$ & $26(12.7 \%)$ \\
\hline Memantine & $26(7.2 \%)$ & $10(4.9 \%)$ \\
\hline MMSE score, $m \pm S D$ & $19.6 \pm 4.6$ & $19.7 \pm 4.4$ \\
\hline mini-Zarit score, $\mathrm{m} \pm \mathrm{SD}$ & $3.1 \pm 1.7$ & $3.1 \pm 1.7$ \\
\hline 4-IADL score ( $\geq 2$ activities) & $225(62.4 \%)$ & $123(60.3 \%)$ \\
\hline 5 words test, $\mathrm{m} \pm \mathrm{SD}$ & $5.6 \pm 2.3$ & $5.7 \pm 2.3$ \\
\hline Verbal fluency, $\mathrm{m} \pm \mathrm{SD}$ & $10.7 \pm 5.5$ & $10.5 \pm 5.1$ \\
\hline
\end{tabular}

3 Figures are given as $\mathrm{n}$ and \% unless otherwise specified

4 SD: Standard Deviation 
1 Table 2. Association between baseline characteristics of patients and the risk of rapid

2 cognitive decline. Univariate logistic regression.

\begin{tabular}{|c|c|c|c|c|}
\hline & \multicolumn{2}{|c|}{$\begin{array}{c}\text { Rapid cognitive } \\
\text { decline }\end{array}$} & \multirow[b]{2}{*}{ OR (95\% I.C.) } & \multirow[b]{2}{*}{ p-value } \\
\hline & $\begin{array}{r}\text { Yes } \\
\mathrm{n}=60\end{array}$ & $\begin{array}{r}\text { No } \\
n=144\end{array}$ & & \\
\hline \multicolumn{5}{|l|}{ Sex } \\
\hline Male & $25(29.4)$ & $60(29.4)$ & & \\
\hline Female & $35(70.6)$ & $84(70.6)$ & n.a & \\
\hline \multicolumn{5}{|l|}{ Age } \\
\hline$<75$ years old & $16(26.7)$ & $43(29.9)$ & 1.00 & \\
\hline$>=75$ years old & $44(73.3)$ & $101(70.1)$ & $1.17(0.60-2.30)$ & 0.647 \\
\hline \multicolumn{5}{|l|}{ Residential status } \\
\hline Out-patients & $44(73.3)$ & $125(86.8)$ & 1.00 & \\
\hline Institution & $16(26.7)$ & $19(13.2)$ & $2.39(1.13-5.06)$ & 0.022 \\
\hline \multicolumn{5}{|l|}{ Level of education } \\
\hline primary or short secondary school & $22(36.7)$ & $31(21.5)$ & 1.00 & \\
\hline long secondary school & $38(63.3)$ & $113(78.5)$ & $2.11(1.09-4.08)$ & 0.026 \\
\hline \multicolumn{5}{|l|}{ BMI } \\
\hline$<18.5 \mathrm{~kg} / \mathrm{m}^{2}$ & $9(23.1)$ & $30(20.8)$ & $0.68(0.26-1.78)$ & 0.432 \\
\hline $18<=\mathrm{BMI}<25 \mathrm{~kg} / \mathrm{m}^{2}$ & $15(30.6)$ & $34(23.6)$ & 1.00 & \\
\hline$>=25 \mathrm{~kg} / \mathrm{m}^{2}$ & $36(60.0)$ & $80(55.6)$ & $1.02(0.50-2.10)$ & 0.957 \\
\hline \multicolumn{5}{|l|}{ MMSE } \\
\hline$>=20$ & $35(58.3)$ & $78(34.2)$ & 1.00 & \\
\hline$<20$ & $25(41.7)$ & $66(45.8)$ & $0.84(0.46-1.55)$ & 0.586 \\
\hline \multicolumn{5}{|l|}{ Verbal fluency } \\
\hline$>=15$ & $12(20.3)$ & 27 (18.9) & 1.00 & \\
\hline$<15$ & $47(79.7)$ & $116(81.1)$ & $0.91(0.43-1.95)$ & 0.811 \\
\hline \multicolumn{5}{|l|}{5 words } \\
\hline$>=8$ & $10(16.7)$ & $36(25.2)$ & 1.00 & \\
\hline$<8$ & $50(83.3)$ & $107(74.8)$ & $1.68(0.77-3.66)$ & 0.190 \\
\hline \multicolumn{5}{|l|}{ Clock } \\
\hline$>2$ & $22(37.9)$ & $48(35.6)$ & 1.00 & \\
\hline$<=2$ & $36(62.1)$ & $95(66.4)$ & $0.83(0.44-1.56)$ & 0.557 \\
\hline \multicolumn{5}{|l|}{ Symptoms } \\
\hline Agitation & $13(21.7)$ & $22(15.3)$ & $1.72(0.76-3.93)^{*}$ & 0.194 \\
\hline Hallucination & $9(15.0)$ & $16(11.1)$ & $1.64(0.65-4.18)^{*}$ & 0.298 \\
\hline Strolling & $6(10.0)$ & $13(9.0)$ & $1.35(0.46-3.92)^{*}$ & 0.584 \\
\hline Depression & $14(23.3)$ & $38(26.4)$ & $1.08(0.50-2.31)^{*}$ & 0.851 \\
\hline EPS & $6(10.0)$ & $18(12.5)$ & $0.97(0.35-2.73)^{*}$ & 0.959 \\
\hline \multicolumn{5}{|l|}{ Loss of autonomy for at least 2 activities } \\
\hline No & $18(30.0)$ & $63(43.8)$ & 1.00 & \\
\hline Yes & $42(70.0)$ & $81(56.2)$ & $1.81(0.95-3.45)$ & 0.069 \\
\hline \multicolumn{5}{|l|}{ Previous ChEI treatment } \\
\hline No & $32(53.3)$ & $83(57.6)$ & 1.00 & \\
\hline Yes & $28(46.7)$ & $61(42.4)$ & $1.19(0.65-2.18)$ & 0.572 \\
\hline \multicolumn{5}{|c|}{ Loss $>=3$ points on MMSE in the previous year } \\
\hline No & $10(29.4)$ & $33(49.3)$ & 1.00 & \\
\hline Yes & $24(70.6)$ & $34(50.8)$ & $2.33(0.97-5.61)$ & 0.060 \\
\hline
\end{tabular}

* Compared with none trouble 
Table 3. Risk of rapid decline in two multivariate logistic regression analyses

\begin{tabular}{|c|c|c|c|c|}
\hline & \multicolumn{2}{|c|}{ Model $1(n=204)$} & \multicolumn{2}{|c|}{ Model $2(n=101)$} \\
\hline & OR (95\% I.C.) & p-value & OR (95\%I.C.) & p-value \\
\hline \multicolumn{5}{|l|}{ Residential status } \\
\hline Out-patients & 1.00 & & 1.00 & \\
\hline Institution & $1.95(0.89-4.31)$ & 0.097 & $2.88(0.97-8.59)$ & 0.057 \\
\hline \multicolumn{5}{|l|}{ Level of education } \\
\hline Primary or short secondary school & $\mathbf{1 . 0 0}$ & & $\mathbf{1 . 0 0}$ & \\
\hline long secondary school & $2.21(1.12-4.37)$ & 0.022 & $4.94(1.83-13.32)$ & 0.002 \\
\hline \multicolumn{5}{|c|}{ Loss of autonomy for at least 2 activities } \\
\hline No & 1.00 & & 1.00 & \\
\hline yes & $1.71(0.86-3.40)$ & 0.124 & $0.72(0.26-2.01)$ & 0.529 \\
\hline \multicolumn{5}{|c|}{ Loss $>=3$ points on MMSE in the previous year } \\
\hline No & & & 1.00 & \\
\hline yes & & & $2.81(1.03-7.65)$ & $\mathbf{0 . 0 4 3}$ \\
\hline
\end{tabular}


Table 4. Association between baseline characteristics of patients and the Deco score

\begin{tabular}{lrrr}
\hline Sex & m & sd & p-value \\
$\quad$ Male & & & \\
$\quad$ Female & 18,5 & 9,1 & 0,618 \\
Age $\quad 19,2$ & 8,7 & \\
$\quad<75$ years old & & & \\
$\quad>=75$ years old & 19,1 & 8,8 & 0,803 \\
Residential status & 18,8 & 8,9 & \\
$\quad$ Out-patients & 18,8 & 8,8 & 0,727 \\
$\quad$ Institution & 19,6 & 9,6 & \\
Level of education & & & \\
$\quad$ Primary or short secondary school & 19,1 & 9,1 & 0,388 \\
$\quad$ long secondary school & 18,3 & 8,1 & \\
Loss of autonomy for at least 2 activities & & & \\
$\quad$ No & 20,3 & 8,6 & $\mathbf{0 , 0 7 1}$ \\
$\quad$ yes & 17,9 & 8,9 & \\
Rapid decline between inclusion and 12-month visit & & \\
$\quad$ No & 20,2 & 8,9 & $\mathbf{0 , 0 0 0 8}$ \\
$\quad$ yes & 15,1 & 7,4 & \\
\hline
\end{tabular}


Table 5. Predictive power of 3 thresholds of the Deco score. Univariate logistic regression.

\section{RCD}

\begin{tabular}{lrrllllll} 
& Yes & No & OR (95\%I.C.) & p-value & Se & Sp & PPV & NPV \\
\hline DECO $>16$ & $17(37.8)$ & $85(64.4)$ & 1.00 & & & & & \\
DECO $<=16$ & $28(62.2)$ & $47(35.6)$ & $2.98(1.46-6.00)$ & 0.002 & 62.2 & 64.4 & 37.3 & 83.3 \\
& & & & & & & & \\
DECO $>17$ & $16(35.6)$ & $79(64.4)$ & 1.00 & & & & \\
DECO $<=17$ & $29(59.9)$ & $53(40.2)$ & $2.70(1.34-5.46)$ & 0.006 & 64.4 & 59.9 & 35.4 & 83.2 \\
& & & & & & & & \\
DECO $>18$ & $15(33.3)$ & $72(54.6)$ & 1.00 & & & & & \\
DECO $<=18$ & $30(66.7)$ & $60(45.5)$ & $2.40(1.18-4.87)$ & 0.015 & 66.7 & 54.6 & 33.3 & 82.8 \\
\hline
\end{tabular}

RCD states for rapid cognitive decline, Se for sensitivity, Sp for specificity, PPV for positive predictive value, NPV for negative predictive value 
Table 6. Best predictive thresholds of the Deco score according to age-groups. Univariate logistic regression.

\begin{tabular}{|c|c|c|c|c|c|c|c|c|}
\hline & \multicolumn{2}{|c|}{ RCD } & \multirow[b]{2}{*}{ OR (95\% I.C.) } & \multirow[b]{2}{*}{ p-value } & \multirow[b]{2}{*}{ Se } & \multirow[b]{2}{*}{ Sp } & \multirow[b]{2}{*}{ VPP } & \multirow[b]{2}{*}{ VPN } \\
\hline & Yes & No & & & & & & \\
\hline \multicolumn{9}{|l|}{ Age $<75$ yrs old } \\
\hline $\mathrm{DECO}>16$ & $4(26.7)$ & $29(70.7)$ & 1.00 & & & & & \\
\hline $\mathrm{DECO}<=16$ & $11(73.3)$ & $12(29.3)$ & $6.65(1.76-25.1)$ & 0.005 & 73.3 & 70.7 & 47.8 & 87.9 \\
\hline \multicolumn{9}{|l|}{ Age $>=75$ yrs old } \\
\hline $\mathrm{DECO}>14$ & $14(17.5)$ & $66(82.5)$ & 1.00 & & & & & \\
\hline DECO $<=14$ & $16(39.0)$ & $25(61.0)$ & $3.02(1.29-7.08)$ & 0.011 & 57.8 & 74.2 & 43.3 & 83.8 \\
\hline
\end{tabular}




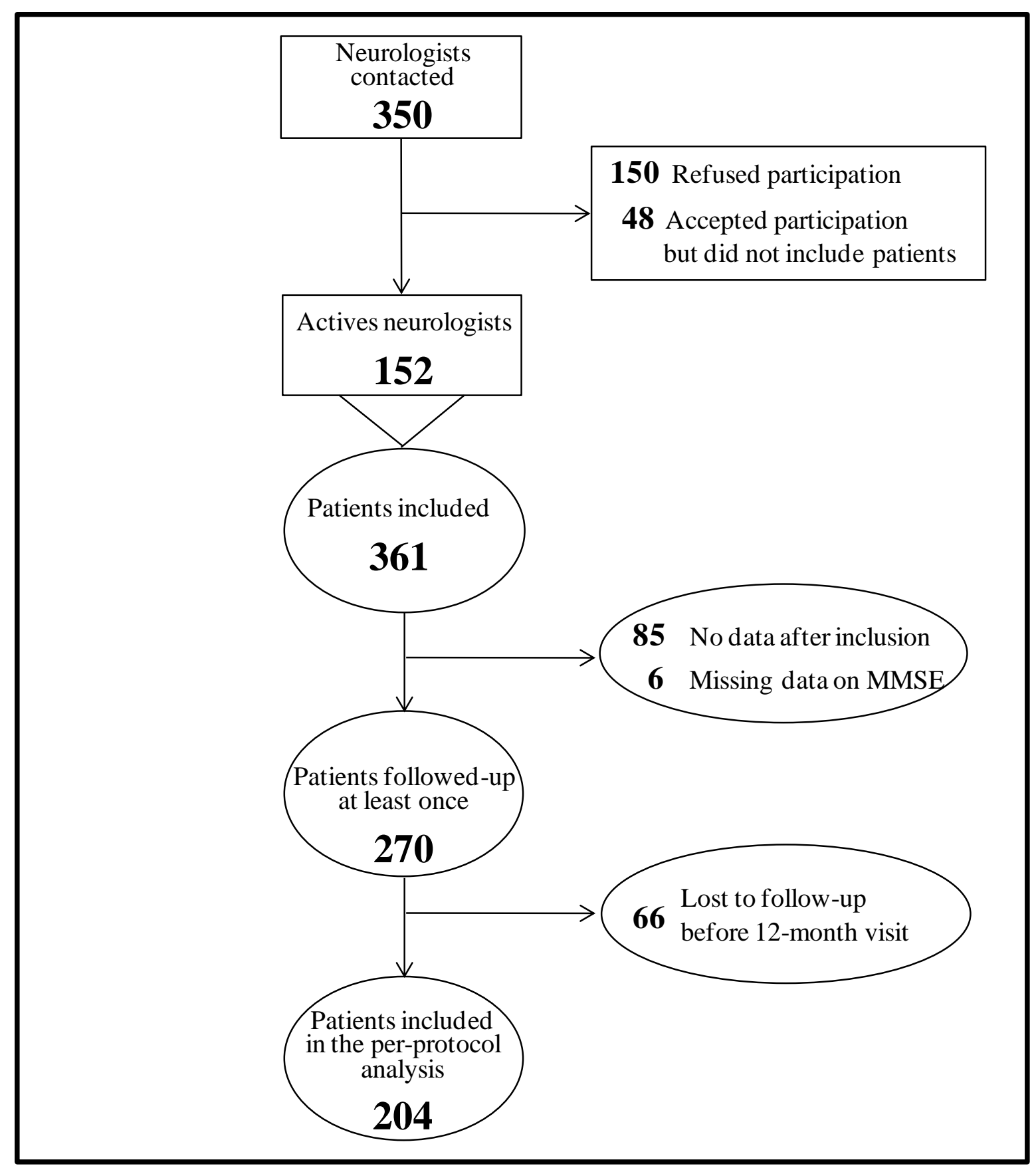

Figure 1: Flow chart of the patients' selection for the per-protocol analysis 
Approximate area under curve $=0.667$

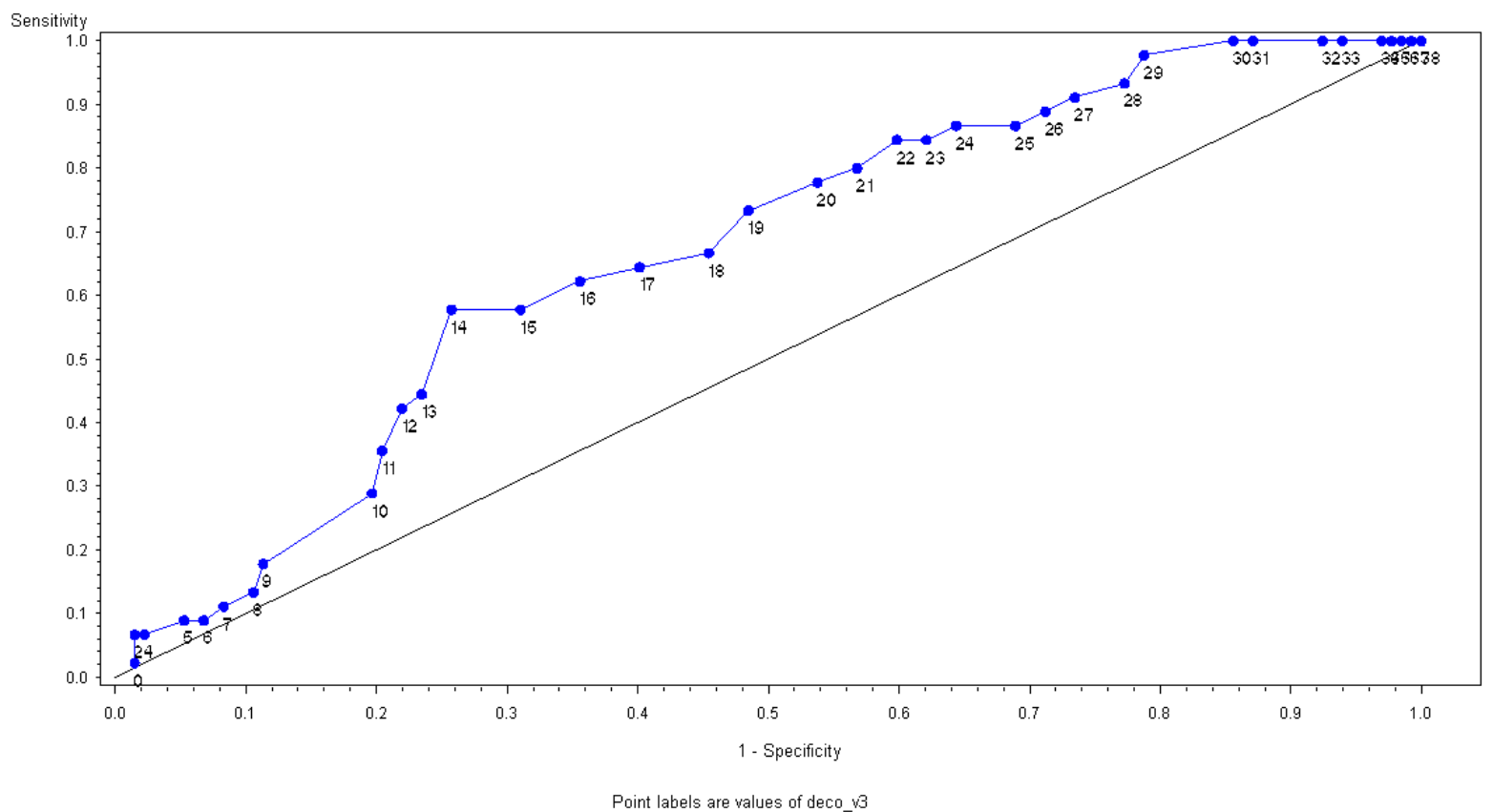

Figure 2: ROC curve for the prediction of rapid cognitive decline according to DECO scores 